Article

\title{
Effect of Citrus Fiber on the Rheological Properties of Dough and Quality of the Gluten-Free Bread
}

\author{
Jarosław Korus $^{1}$, Lesław Juszczak ${ }^{2}\left(\mathbb{D}\right.$, Mariusz Witczak ${ }^{3}\left(\mathbb{D}\right.$ and Rafał Ziobro ${ }^{1, *(1)}$ \\ 1 Department of Carbohydrate Technology, Faculty of Food Technology, University of Agriculture in Krakow, \\ Balicka 122, 30-149 Kraków, Poland; rrkorus@cyf-kr.edu.pl \\ 2 Department of Food Analysis and Evaluation of Food Quality, Faculty of Food Technology, \\ University of Agriculture in Krakow, Balicka 122, 30-149 Kraków, Poland; rrjuszcz@cyf-kr.edu.pl \\ 3 Department of Engineering and Machinery for Food Industry, Faculty of Food Technology, \\ University of Agriculture in Krakow, Balicka 122, 30-149 Kraków, Poland; rrwitcza@cyf-kr.edu.pl \\ * Correspondence: rrziobro@cyf-kr.edu.pl
}

Received: 6 August 2020; Accepted: 20 September 2020; Published: 23 September 2020

check for updates

\begin{abstract}
The aim of the study was to evaluate the use of citrus fiber for the nutritional enrichment and technological improvement of gluten-free bread. A partial replacement of starch in bread formulation was analyzed in terms of the dough's rheological properties and selected quality parameters of the bread. The results allowed to conclude that the presence of citrus fiber modifies the rheological properties of the dough, causing an increase in storage modulus $\left(\mathrm{G}^{\prime}\right)$ and loss modulus $\left(G^{\prime \prime}\right)$ values, as well as zero shear viscosity, accompanied with a decrease in instantaneous compliance $\left(\mathrm{J}_{0}\right)$ and viscoelastic compliance $\left(\mathrm{J}_{1}\right)$ to the applied stress, which reflects dough strengthening caused by significantly greater water binding and swelling properties characteristic of this ingredient. The introduction of the citrus fiber to bread formulations caused a significant decrease in bread volume and structure changes in crumb visible in the larger porosity and average pore size. The presence of citrus fiber affected texture, decreasing crumb hardness, springiness, cohesiveness and chewiness in comparison to the control. It could also be observed that the use of citrus fiber results in limited crumb hardening during storage, which indicates that this component could be an effective factor retarding the staling of the gluten-free bread based on starch and hydrocolloids.
\end{abstract}

Keywords: gluten-free dough; citrus fiber; rheological properties; bread quality

\section{Introduction}

The occurrence of common diet-related diseases is often triggered by improper lifestyle and nutrition. A number of problems could be caused by diets rich in highly refined products and deprived of low processed plant foods containing high levels of dietary fiber [1]. The consumption of foods rich in dietary fiber is insufficient, hence there is a need to enrich food, including bread, with fiber preparations of various origin [2]. Fiber preparations, used in the production of functional food, apart from their beneficial effect on the human body, positively impact the texture, sensory and functional characteristics of the products [3].

Properties of gluten-free bread, in which starch is the major component, are predominantly determined by characteristics of this polymer [4,5]. Consequently, the nutritional value of such products is relatively low. The studies performed in vitro on resistant starch present in gluten-free bread by Matos Segura and Rosell [6] showed that the main fraction of starch is rapidly digested (92.5\%), which corresponds to a glycaemic index up to 96 . On the other hand, the results of Hager and co-workers [7] indicated that the intake of fiber with a gluten-free diet is low, while simple sugars are present in large quantities. Therefore the application of naturally gluten-free components, e.g., 
pseudocereals rich in dietary fiber, as well as the use of fiber preparations produced from various raw materials may significantly increase the consumption of fiber by celiacs.

Studies on the influence of fiber-rich ingredients or preparations on the structure and properties of gluten-free dough and bread are quite widely described in the literature. This is due, on the one hand, to the very broad range of ingredients or preparations rich in fiber, and, on the other hand, to the variety of raw materials, recipes and technologies for obtaining gluten-free products [8,9]. A natural way to increase the content of fiber in gluten-free bread is to introduce a suitable flour from gluten-free sources into the recipe. Such flours, depending on their origin, may contain significant amounts of dietary fiber and its individual fractions, and their use, in addition to improving nutritional value, may have a beneficial effect on the physicochemical characteristics and sensory qualities [10]. Korus et al. [11], while examining the influence of acorn flour on the dough properties and characteristics of gluten-free starch based bread, concluded that apart from the nutritional effect, i.e., an increase in the content of particular nutrients, including dietary fiber, the additive could have a positive effect on the increase in bread volume and crumb structure, and furthermore limit its staling. In another study, it was observed that the presence of hemp flour in the recipe of gluten-free bread could significantly increase the content of dietary fiber and its fractions, and reduce crumb hardness and amylopectin recrystallization, limiting bread staling [12].

An elevated content of dietary fiber in dough and then in bread not only improves nutritional value, but also affects sensory and physicochemical properties, including water retention and rate of bread staling [13-17]. Fruit-derived dietary fiber is often considered as a potential ingredient of bakery products and has been intensively investigated [18]. The main benefits of citrus fiber in comparison to other sources is a higher level of soluble fractions, reaching up to 33\% [19]. Bakery products enriched in citrus fiber include biscuits [20,21], muffins [22,23], and bread [24,25], including gluten-free formulations based on rice flour with potato starch [26,27] and corn starch with corn gluten meal [28].

Due to very diverse sources of fiber preparations and other ingredients of bread and the technology of its production, the influence of enriching gluten-free bread with dietary fiber is still problematic [29,30]. Therefore, the aim of this study was to analyze the influence of commercially available citrus fiber on the rheological properties of dough and the structure and characteristics of gluten-free bread based on a mixture of corn and potato starch.

\section{Materials and Methods}

\subsection{Materials}

Study material consisted of corn starch (Bezgluten, Posadza, Poland), potato starch (Pepees S.A., Łomża, Poland), guar gum (Lotus Gums and Chemicals, Jodhpur, India), pectin (Pektowin, Jasło, Poland), citrus fiber (ZPH Corso, Sieraków, Poland), freeze-dried yeasts (S.I. Lesaffre, Marcq-en-Baroeul, France), sugar, salt, plant oil (from local store) and tap water.

\subsection{Methods}

\subsubsection{Gluten-Free Bread Formulation}

The dough used for gluten-free bread baking was obtained using the following ingredients: corn starch and potato starch (mixed at a ration 4:1) $690 \mathrm{~g}$, freeze-dried yeasts $34.5 \mathrm{~g}$, plant oil $20.7 \mathrm{~g}$, sucrose $13.8 \mathrm{~g}$, salt $11.5 \mathrm{~g}$, pectin $11.5 \mathrm{~g}$, guar gum $11.5 \mathrm{~g}$ and tap water $656 \mathrm{~g}$. Part of the starch (proportional amounts of corn and potato starch), at levels of 10,15 or $20 \%$, was replaced with citrus fiber preparation. Since the preliminary rheological analyses showed a significant effect of the applied fiber preparation on the water absorption of the dough, a variable amount of water was used for the preparation of baking mixtures, the level of which was determined on the basis of the results of the preliminary back extrusion test carried out using a texture analyzer (TA-XT+, Stable Micro Systems, Surrey, UK) 
equipped with an adapter A/BE-d 35. Based on the results, the addition of water to individual recipes was between $1161 \mathrm{~g}$ for a $10 \%$ addition level of citrus fiber and $1667 \mathrm{~g}$ in the case of a $20 \%$ addition level.

\subsubsection{Rheological Properties of the Dough}

An oscillatory rheometer MARS II (Thermo-Haake, Karlsruhe, Germany), working at $25{ }^{\circ} \mathrm{C}$, was used to determine the rheological properties of the dough. Prior to the measurement, the samples (without yeasts) were placed in a set of parallel plates (diameter $35 \mathrm{~mm}$, gap size $1 \mathrm{~mm}$ ) and left for $5 \mathrm{~min}$ to stabilize temperature and allow stress relaxation.

Mechanical spectra were determined in the range of linear viscoelasticity at a constant strain amplitude of $0.1 \%$ with an angular frequency in the range of 1-100 rad/s. Experimental data were described using power law equations:

$$
\begin{aligned}
G^{\prime}(\omega) & =K^{\prime} \cdot \omega^{n^{\prime}} \\
G^{\prime \prime}(\omega) & =K^{\prime \prime} \cdot \omega^{n^{\prime \prime}}
\end{aligned}
$$

where: $G^{\prime}$-storage modulus (Pa), $G^{\prime \prime}$-loss modulus $(\mathrm{Pa}), \omega$-angular frequency $(\mathrm{rad} / \mathrm{s}), K^{\prime}, K^{\prime \prime}, n^{\prime}$, $n^{\prime \prime}$ - constants.

Creep and recovery tests were conducted at constant strain in creep phase $\tau_{0}=2$ Pa over $150 \mathrm{~s}$. The recovery phase lasted for $300 \mathrm{~s}$. Burgers' model was used to fit the experimental data:

$$
\begin{gathered}
J(t)=J_{0}+\frac{t}{\eta_{0}}+J_{1} \cdot\left(1-\exp ^{-t / \lambda_{\mathrm{ret}}}\right) \text { for a creep phase } \\
J(t)=\frac{t_{1}}{\eta_{0}}-J_{1} \cdot\left(1-\exp ^{t_{1} / \lambda_{\mathrm{ret}}}\right) \cdot \exp ^{-t / \lambda_{\mathrm{ret}}} \text { for a recovery phase }
\end{gathered}
$$

where: $J$-compliance $\left(\mathrm{Pa}^{-1}\right), J_{0}$-instantaneous compliance $\left(\mathrm{Pa}^{-1}\right), J_{1}$-viscoelastic compliance $\left(\mathrm{Pa}^{-1}\right)$, $\eta_{0}$ —zero shear viscosity (Pa.s), $\lambda_{\text {ret }}$-retardation time (s), $t_{1}$ 一time of stress removal (s).

Additionally, the recovery value was calculated based on Equation (5):

$$
R(\%)=\left(\frac{J_{0} \cdot J_{1}}{J_{\max }}\right) \cdot 100
$$

where: $J_{0}$-instantaneous compliance $\left(\mathrm{Pa}^{-1}\right), J_{1}$-viscoelastic compliance $\left(\mathrm{Pa}^{-1}\right), J_{\max }$-maximum compliance in the creep phase $\left(\mathrm{Pa}^{-1}\right)$.

Viscosity curves were determined at a controlled shear rate in the range of $1-100 \mathrm{~s}^{-1}$. The experimental data were fitted with a power law model:

$$
\eta_{a p}=K \cdot \dot{\gamma}^{n}
$$

where: $\eta_{a p}$ —apparent viscosisty (Pa.s), K—consistency coefficient $\left(\mathrm{Pa} \cdot \mathrm{s}^{\mathrm{n}}\right), \dot{\gamma}$ - shear rate $\left(\mathrm{s}^{-1}\right), n$-flow behavior index.

\subsubsection{Dough Preparation and Baking}

After weighing, all ingredients were mixed for $8 \mathrm{~min}$ (Laboratory Spiral Mixer SP 12, Diosna, Osnabrück, Germany). The dough was fermented for $15 \min \left(35^{\circ} \mathrm{C}, 80 \%\right.$ relative humidity) and re-mixed for $1 \mathrm{~min}$. Dough samples of $50 \mathrm{~g}$ were put into greased metal pans and proofed for another $20 \mathrm{~min}$ as described above. The loaves were baked for $30 \mathrm{~min}$ at $230^{\circ} \mathrm{C}$ (electric oven MIWE Condo type CO 2 0608, MIWE GmbH, Arnstein, Germany). After baking, the loaves were removed from pans, cooled at an ambient temperature and used for further analyses. In order to evaluate the texture changes, some loaves were stored in polyethylene bags at $22 \pm 2{ }^{\circ} \mathrm{C}$. 


\subsubsection{Bread Analysis}

Bread volume was evaluated using Volscan 600 (Stable Micro Systems, Surrey, UK). A digital image analysis was applied to scans of bread slices (thickness $1 \mathrm{~cm}$, cut from the internal part of each loaf) The images were processed using ImageJ v. 1.44c software, taking into account porosity, pore density and the average size of the pores.

Bread crumb was characterized by texture profile analysis (TPA) performed using a texture analyzer TA-XT2plus (Stable Micro Systems, Surrey, UK) at the compression speed $5 \mathrm{~mm} / \mathrm{s}$. A crumb sample with $2 \mathrm{~cm}$ height and $2 \mathrm{~cm}$ diameter was compressed to $50 \%$ deformation using an aluminum probe $\mathrm{P} / 20$ in two cycles. The obtained values of hardness, springiness, cohesiveness and chewiness were used as indicators of texture changes during storage. The analyses were conducted 2, 24 and $48 \mathrm{~h}$ after baking.

\subsubsection{Statistical Analysis}

In order to assess the significance of the differences between the averages, the data were subjected to a single-factor analysis of variance and the differences between the averages were determined using Duncan's post hoc test at a significance level of 0.05. The two-factor ANOVA was used to determine the effect of citrus fiber addition level and storage time on texture parameters. The relationships between the analyzed parameters were evaluated using the values of Pearson's correlation coefficients. Statistica 11.0 (StatSoft Inc., Tulsa, OK, USA; StatSoft Polska Sp. z o.o., Kraków, Poland) was used for calculations.

\section{Results and Discussion}

\subsection{Rheological Properties of Dough}

The rheological characteristics of the dough, and especially the evaluation of its viscoelastic properties, enable the quantification of the influence of changes in bread formulation. Gluten-free dough based on starch typically behaves as a weak gel in the region of small deformations [4]. Mechanical spectra, showing a dependence of the storage modulus $\left(G^{\prime}\right)$ and loss modulus $\left(G^{\prime \prime}\right)$ on angular frequency $(\omega)$, are shown in Figure 1a.

In all cases, the values of the storage modulus dominated over the values of the loss modulus $\left(\mathrm{G}^{\prime}\right.$ $>G^{\prime \prime}$ ), indicating the viscoelastic character of the dough. The proportion of citrus fiber modified the viscoelastic characteristics of the samples, causing an increase in the values of both modules, with the greatest influence being observed for the highest concentration of fiber. The significant dependence of $G^{\prime}$ and $G^{\prime \prime}$ modules on angular frequency and their relative changes are confirmed by the values of the phase shift tangent $(0.1<\tan \delta<1)$ (Figure $1 \mathrm{~b}$ ), indicating the characteristics of weak gels, which confirms previous observations for gluten-free systems [4,31]. The share of citrus fiber in the amount of $15-20 \%$ significantly decreased the values of $\tan \delta$, indicating a strengthening of the dough structure. In an earlier study conducted by O'Shea and co-authors [26], a $5.5 \mathrm{~g}$ addition of orange pomace to the formulation based on $100 \mathrm{~g}$ of rice flour and potato starch also resulted in an increase in stiffer or stronger batter.

The parameters of power models describing the changes in the value of storage and loss modules in relation to angular frequency are presented in Table 1 . The lowest values of $K^{\prime}$ and $K^{\prime \prime}$ constants corresponding to the initial values of $G^{\prime}$ and $G^{\prime \prime}$ modules were found for the control (Table 1). Partial replacement of starch with citrus fiber in the amount of $10 \%$ even with simultaneous increase in the amount of added water did not significantly affect the changes in the rheological characteristics of the dough. On the other hand, a higher share of fiber in the recipe (15-20\%) resulted in a significant increase in $\mathrm{K}^{\prime}$ and $\mathrm{K}^{\prime}$ parameters. (Table 1), confirming at the same time the increase in the share of both elastic and viscous characteristics. A significant decrease in the tangent value of the phase shift angle (Table 1) also indicates a strengthening of dough structure under the influence of $15-20 \%$ fiber, which is a component with a high swelling capacity. The presence of citrus fiber had only a slight 
effect on the values of $\mathrm{n}^{\prime}$, which indicates the dependence of the value of the storage modulus on the angular frequency, and only its greatest share caused a significant decrease in the value of this parameter (Table 1). On the other hand, the values of the $n^{\prime}$ parameter increased significantly with the amount of fiber in the system (Table 1), indicating an increase in the dependence of the $G^{\prime}$ module, exhibiting the viscous character of the system, on angular frequency.

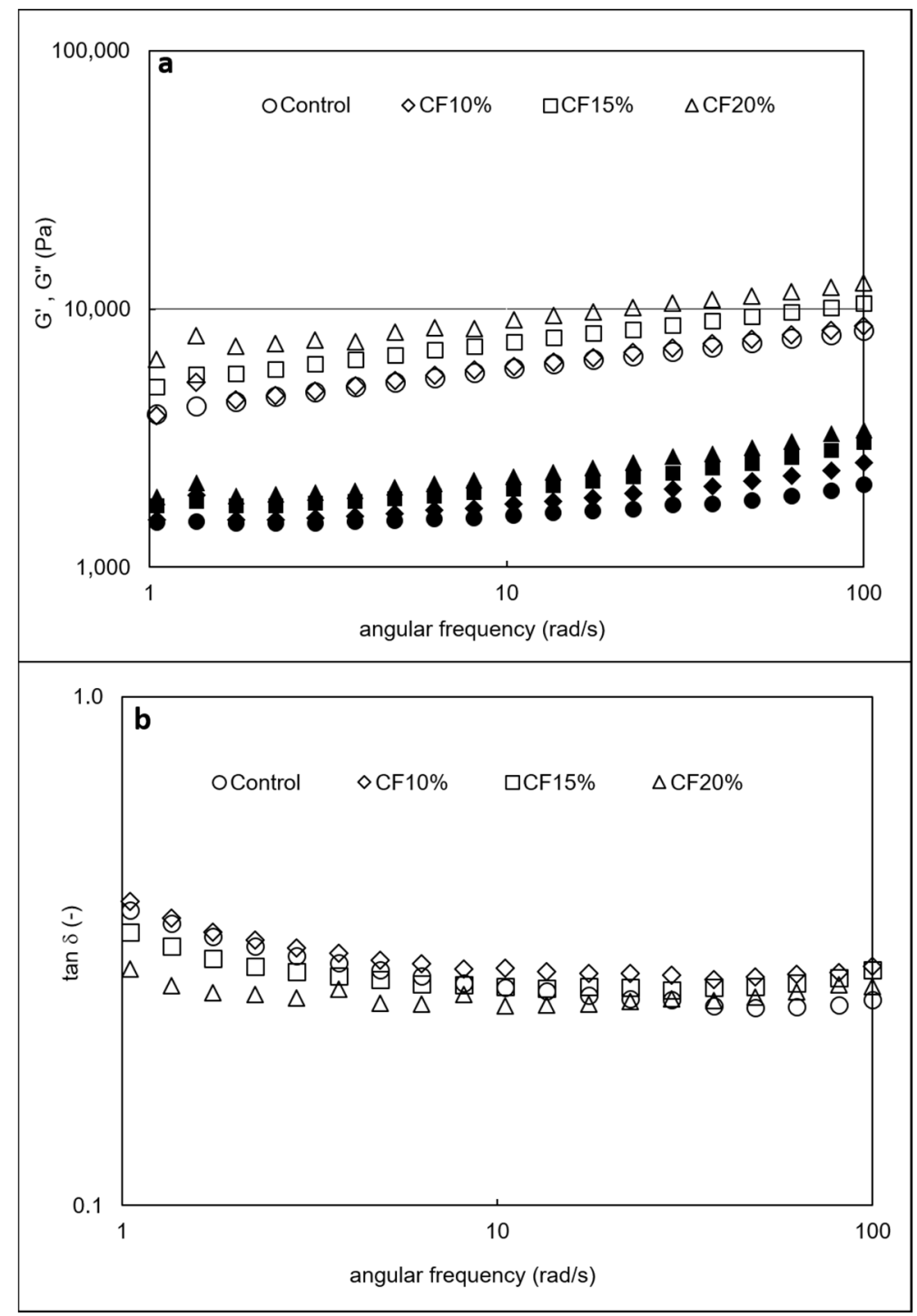

Figure 1. Mechanical spectra (a) and tangent of shift angle ( $\left.\tan \delta=G^{\prime \prime} / G^{\prime}\right)(\mathbf{b})$ of control gluten-free dough and samples with citrus fiber, $\mathrm{G}^{\prime}$ - filled symbols, $\mathrm{G}^{\prime \prime}$ - empty symbols. 
Table 1. Parameters of the rheological models describing control gluten-free dough and samples with citrus fiber $(\mathrm{CF})$ addition.

\begin{tabular}{|c|c|c|c|c|}
\hline Parameter & Control GFB & $10 \% \mathrm{CF}$ & $15 \% \mathrm{CF}$ & $20 \% \mathrm{CF}$ \\
\hline $\mathrm{K}^{\prime}\left(\mathrm{Pa} \cdot \mathrm{s}^{\mathrm{n}^{\prime}}\right)$ & $4017.0 \pm 138.4^{a}$ & $4024.1 \pm 489.0^{a}$ & $5156.7 \pm 411.8^{b}$ & $6503.5 \pm 492.1^{\mathrm{c}}$ \\
\hline $\mathrm{n}^{\prime}(-)$ & $0.158 \pm 0.003^{b, c}$ & $0.166 \pm 0.006^{c}$ & $0.154 \pm 0.001^{b}$ & $0.142 \pm 0.006^{a}$ \\
\hline$r^{2}>$ & 0.996 & 0.995 & 0.996 & 0.994 \\
\hline $\mathrm{K}^{\prime \prime}\left(\mathrm{Pa} \cdot \mathrm{s}^{\mathrm{n}^{\prime \prime}}\right)$ & $1385.6 \pm 51.3^{a}$ & $1382.7 \pm 138.4^{\mathrm{a}}$ & $1557.2 \pm 125.4^{\mathrm{a}, \mathrm{b}}$ & $1687.4 \pm 140.4^{b}$ \\
\hline $\mathrm{n}^{\prime \prime}(-)$ & $0.071 \pm 0.004^{\mathrm{a}}$ & $0.114 \pm 0.003^{b}$ & $0.125 \pm 0.004^{c}$ & $0.139 \pm 0.007^{d}$ \\
\hline$r^{2}>$ & 0.858 & 0.938 & 0.940 & 0.939 \\
\hline $\operatorname{Tan} \delta^{\mathrm{TM}}$ at $1 \mathrm{~Hz}$ & $0.380 \pm 0.004^{c}$ & $0.396 \pm 0.008^{d}$ & $0.344 \pm 0.007^{b}$ & $0.292 \pm 0.002^{a}$ \\
\hline $\mathrm{J}_{0} 10^{4}\left(\mathrm{~Pa}^{-1}\right)$ & $3.40 \pm 0.23^{b}$ & $2.96 \pm 0.17^{b}$ & $2.04 \pm 0.18^{a}$ & $1.66 \pm 0.11^{a}$ \\
\hline$\eta_{0}(\mathrm{KPa} \cdot \mathrm{s})$ & $286.1 \pm 11.5^{a}$ & $536.5 \pm 61.5^{a}$ & $1135.1 \pm 98.5^{b}$ & $1751.0 \pm 107.5^{\mathrm{c}}$ \\
\hline $\mathrm{J}_{1} 10^{4}\left(\mathrm{~Pa}^{-1}\right)$ & $4.55 \pm 0.21^{c}$ & $3.69 \pm 0.31^{b}$ & $1.98 \pm 0.23^{a}$ & $1.42 \pm 0.21^{\mathrm{a}}$ \\
\hline$\lambda_{\text {ret }}(\mathrm{s})$ & $71.8 \pm 0.9^{a}$ & $70.7 \pm 1.7^{a}$ & $67.8 \pm 6.1^{a}$ & $64.8 \pm 5.4^{\mathrm{a}}$ \\
\hline$r^{2}>$ & 0.991 & 0.993 & 0.994 & 0.995 \\
\hline $\mathrm{R}(\%)$ & 65.38 & 75.74 & 76.43 & 88.51 \\
\hline $\mathrm{K}\left(\mathrm{Pa} \cdot \mathrm{s}^{\mathrm{n}}\right)$ & $702.1 \pm 8.6^{a}$ & $428.0 \pm 28.8^{b}$ & $413.7 \pm 14.8^{b}$ & $391.3 \pm 31.0^{b}$ \\
\hline $\mathrm{n}(-)$ & $0.312 \pm 0.009^{c}$ & $0.264 \pm 0.005^{b}$ & $0.249 \pm 0.003^{a}$ & $0.257 \pm 0.011^{\mathrm{a}, \mathrm{b}}$ \\
\hline$r^{2}>$ & 0.996 & 0.995 & 0.996 & 0.994 \\
\hline
\end{tabular}

Mean value of three replications \pm standard deviation. Mean values signed the same letters in particular rows are not significantly different at 0.05 level of confidence.

The creep and recovery curves of control dough and samples with an increasing share of citrus fiber are shown in Figure 2. The control sample was most susceptible to the applied stress. With an increasing proportion of citrus fiber in the bread recipe, the susceptibility of the dough to the applied stress was significantly reduced. This confirms the results obtained with the oscillatory method (Figure 1a,b) and indicates a strengthening of the dough structure and a lower susceptibility to small deformations in spite of the much greater addition of water. Observations concerning creep and return curves are confirmed by the values of parameters of the Burgers model, which are summarized in Table 1. The largest values of instantaneous compliance $\left(\mathrm{J}_{0}\right)$ and viscoelastic compliance $\left(\mathrm{J}_{1}\right)$ were calculated for control dough. Increasing the share of citrus fiber in the recipe significantly decreased the values of susceptibility to the applied stress (Table 1), indicating a strengthening of the system structure in the area of small deformations by the addition of a highly water-absorbent component. Additionally, the level of fiber alone was in some cases a significant factor responsible for a reduction in $\mathrm{J}_{0}$ and $\mathrm{J}_{1}$. In the case of instantaneous compliance, a significant influence of fiber could be observed for the $10 \%$ and $20 \%$ addition level, and in the case of viscoelastic compliance for $10 \%$ and $15 \%$. The results indicate that the presence of a highly water-absorbent ingredient, citrus fiber, not only improves nutritional value, but also has a structuring effect. This is due to the fact that, despite the increasing water addition, i.e., a significant dilution of the gums used as structuring agents, a strengthening of the dough structure in the range of small deformations is observed, which is illustrated by an increase in the proportion of elastic characteristics (over viscous ones) and a decrease in susceptibility to stress. These observations are also reflected in the zero shear viscosity values (Table 1), which increased especially significantly with $15 \%-20 \%$ fiber. However, no significant effect of the presence of citrus fiber on the retardation time was found. The influence of citrus fiber on the susceptibility of gluten-free dough to applied stress is also confirmed by the recovery values, which increased with the amount of fiber in the system, confirming the strengthening of the dough structure in the area of small deformations and its greater ability to store the energy supplied as stress. 


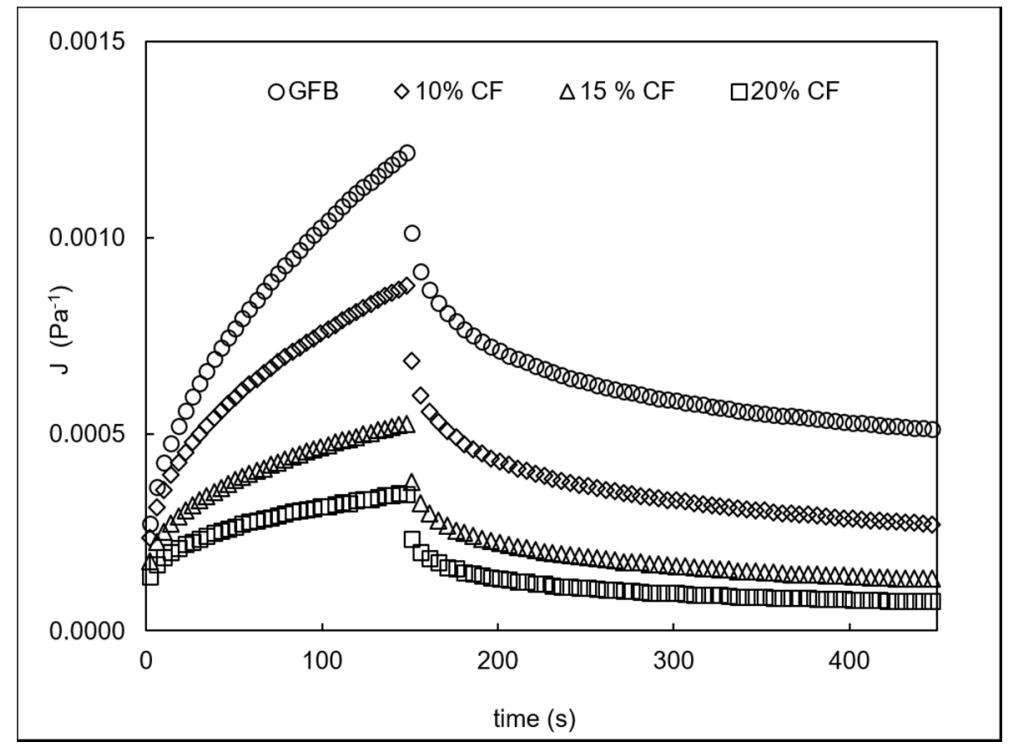

Figure 2. Creep and recovery curves of control gluten-free dough and samples with citrus fiber.

Flow curves of analyzed dough samples are shown in Figure 3. The results indicate the nonnewtonian, shear-thinning (pseudoplastic) behavior of gluten-free dough, which is in agreement with earlier observations concerning these type of dough systems [4]. The parameters of the power model, used to describe experimental viscosity curves, are presented in Table 1. Replacement of a part of starch with citrus fiber caused a significant decrease in apparent viscosity during flow compared to the control test. The viscosity reduction may be the result of a significant increase in water content in doughs, resulting from the high water absorption of added fiber, which at the same time results in a decrease in the concentration of guar gum and pectin used as structure-forming factors. Its introduction to the dough therefore seems to be beneficial not only from a nutritional point of view, but also in terms of improving the rheological characteristics of the dough. Due to the presence of a highly water-absorbent component, the system shows structure strengthening in the area of small deformations, but, on the other hand, at large deformations easily flows, which facilitates deformations during technological processing, e.g., mixing, transport, forming. Observations concerning the decrease in apparent viscosity during flow are confirmed by the values of consistency coefficients set out in Table 1. These values were lower for doughs with citrus fiber than for the control dough, although the level of fiber alone had no significant effect. Additionally, the values of the flow index were significantly lower for doughs with an addition of citrus fiber in comparison with the control sample, indicating their higher pseudoplasticity, i.e., susceptibility to shearing stress in the range of high deformation.

Although the methods used to assess the rheological characteristics of the dough are based on different foundations, the results obtained with their use correlate with each other. Such a negative linear correlation was observed between the values of instantaneous compliance $\mathrm{J}_{0}$ and the parameters of the equations describing the mechanical spectra $K^{\prime}$ and $K^{\prime}(r=-0.93$ and -0.96 , respectively) and viscoelastic compliance $\mathrm{J}_{1}$ and the constants $\mathrm{K}^{\prime}$ and $\mathrm{K}^{\prime}(\mathrm{r}=-0.92$ and -0.95 , respectively). Moreover, zero shear viscosity values positively correlated with $K^{\prime}$ and $K^{\prime}$ parameters $(r=0.98$ and 0.99 , respectively) and negatively with $\tan \delta(\mathrm{r}=-0.95)$. 


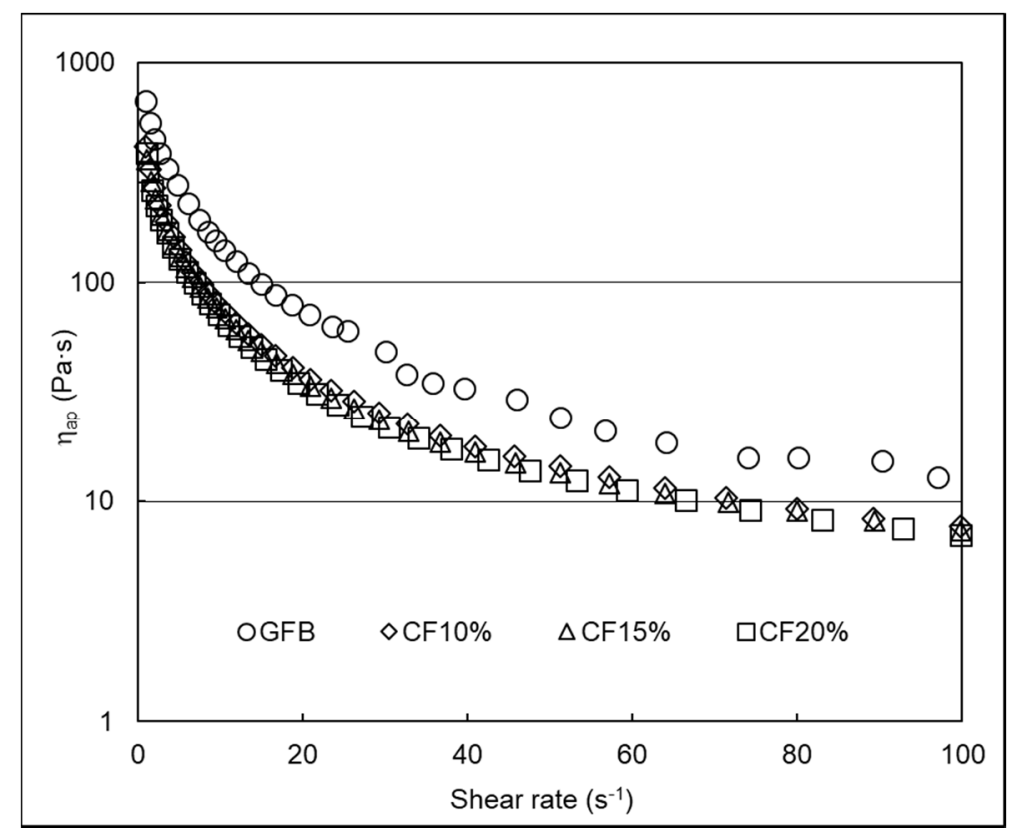

Figure 3. Viscosity (b) curves of control gluten-free dough and samples with citrus fiber.

\subsection{Bread Characteristics}

The basic parameters characterizing the physical properties of control bread and loaves with citrus fiber are summarized in Table 2 . The quality of bread after baking could be initially assessed by the volume of its loaves, and in this case the greatest value was determined for control bread.

Table 2. Bread volume and digital image analysis parameters of control gluten-free dough and samples with citrus fiber (CF) addition.

\begin{tabular}{ccccc}
\hline Sample & Volume $\left(\mathbf{c m}^{\mathbf{3}}\right)$ & Porosity (-) & Cell Density $\left(\mathbf{c m}^{-\mathbf{2}}\right)$ & Average Pore Size $\left.\mathbf{( m m}^{\mathbf{2}}\right)$ \\
\hline Control GFB & $135.8 \pm 6.7^{\mathrm{c}}$ & $0.416 \pm 0.009^{\mathrm{a}}$ & $49.4 \pm 2.4^{\mathrm{d}}$ & $0.84 \pm 0.06^{\mathrm{a}}$ \\
$10 \%$ CF & $110.0 \pm 6.3^{\mathrm{b}}$ & $0.431 \pm 0.007^{\mathrm{a}, \mathrm{b}}$ & $38.1 \pm 1.4^{\mathrm{c}}$ & $1.13 \pm 0.07^{\mathrm{a}, \mathrm{b}}$ \\
$15 \%$ CF & $98.3 \pm 4.1^{\mathrm{a}}$ & $0.436 \pm 0.007^{\mathrm{b}}$ & $32.6 \pm 2.2^{\mathrm{b}}$ & $1.37 \pm 0.15^{\mathrm{b}, \mathrm{c}}$ \\
$20 \%$ CF & $95.0 \pm 5.5^{\mathrm{a}}$ & $0.455 \pm 0.018^{\mathrm{c}}$ & $29.5 \pm 0.8^{\mathrm{a}}$ & $1.56 \pm 0.37^{\mathrm{c}}$ \\
\hline
\end{tabular}

Mean value of four replications \pm standard deviation. Mean values signed the same letters in particular rows are not significantly different at 0.05 level of confidence.

The share of citrus fiber in the recipe significantly reduced the volume of bread. The biggest decrease in volume was recorded when a $10 \%$ share of fiber was applied and reached about $20 \%$. Further increases in the fiber share resulted in a smaller decrease in volume, and at a $20 \%$ concentration of fiber the volume was no longer affected in relation to the sample with a $15 \%$ share. In earlier studies concerning wheat bread [24,25], and gluten-free bread based on rice flour and potato starch with methylcellulose [27], the addition of citrus-derived preparations, resulted in a decrease in bread volume, although the effect visibly depended on the formulation which was used as a control [28]. The key factor affecting the volume of bread is the ability of the dough structure to retain fermentation gases. The presence of citrus fiber significantly increases the water absorption of the dough, forcing the addition of water to bread formulation. This in turn leads to the dilution of structure-forming gums. As a result, the dough is more compact and less flexible, which may limit its ability to retain fermentation gases. The decrease in the volume of bread could be limited or reversed by increasing the addition of the structure-forming gums. The presence of citrus fiber in the bread recipe visibly affected crumb characteristics (Table 2, Figure 4). An increase in the porosity of bread with fiber was observed in relation to the control sample and it was the greater the more fiber was in the recipe 
(Table 2). In parallel to the increase in porosity, the average pore size increased while cell density decreased (Table 2). Similarly, in the study of O'Shea and co-workers, the number of cells decreased with increasing orange pomace levels [27].

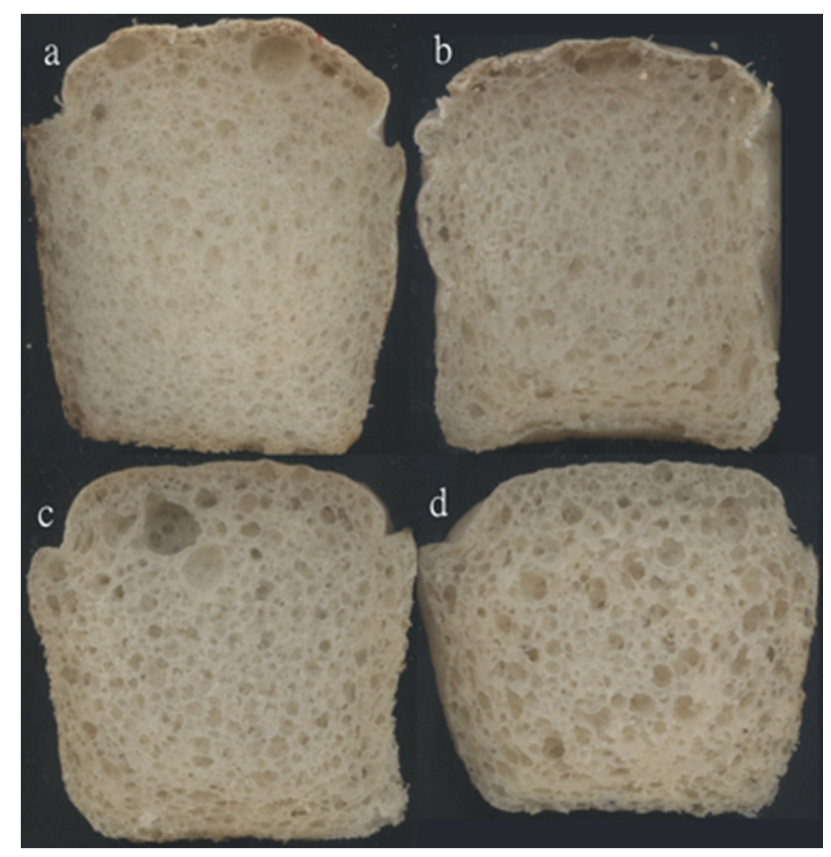

Figure 4. Images of control gluten-free dough (a) and samples with citrus fiber $10 \%$ (b), $15 \%$ (c) and $20 \%(d)$.

The data presented in Table 2 are confirmed by the photographs of the cross-section of the loaves of the analyzed bread shown in Figure 4 . Especially with a higher content of citrus fiber $(15 \%-20 \%)$, a decrease in volume in relation to the control sample (Figure 4a) is clearly visible, as well as an increase in porosity and pore size, with a simultaneous decrease in their density per unit area (Figure $4 c, d$ ). The changes in crumb characteristics are confirmed by the results concerning the decrease in loaf volume due to the introduction of highly water-absorbent fiber and water into the recipe. This resulted in the low elasticity of the dough and limited its ability to retain fermentation gases, which in turn led to fewer larger pores in the crumb due to an easier coalescence of gas bubbles. These observations are confirmed by the correlation coefficients. The values of bread volume correlated strongly and negatively with porosity $(r=-0.85)$ and average pore size $(r=-0.95)$ and positively with cell density $(\mathrm{r}=0.99)$.

\subsection{Crumb Texture}

Measurements of the variability of parameters characterizing the texture during the storage of bread allow the assessment of its stability and the influence of various types of ingredients or additives on its characteristics. During the storage of bread, especially gluten-free bread based on starches of various origins, a number of structural changes, referred to as "staling", may occur, reducing consumer acceptance of such a product. In order to limit this phenomenon, a number of modifications in recipes or technology could be applied to introduce ingredients or additives controlling water retention, modifying the structure of starch polymers and limiting retrogradation $[5,10]$. The parameters characterizing the texture of control bread and samples with citrus fiber are presented in Table 3. 
Table 3. Texture parameters of control bread and samples with citrus fiber (CF) addition.

\begin{tabular}{|c|c|c|c|c|c|}
\hline Sample & Day & Hardness (N) & Springiness- & Cohesiveness- & Chewiness (N) \\
\hline \multirow{3}{*}{ Control GFB } & 1 & $1.12 \pm 0.11^{b}$ & $1.00 \pm 0.00^{\mathrm{d}}$ & $0.90 \pm 0.00^{g}$ & $1.40 \pm 0.26^{c}$ \\
\hline & 2 & $5.57 \pm 0.99^{f}$ & $0.98 \pm 0.01^{\mathrm{c}}$ & $0.63 \pm 0.03^{\mathrm{e}}$ & $3.14 \pm 0.48^{g, h}$ \\
\hline & 3 & $7.42 \pm 0.54 \mathrm{~g}$ & $0.97 \pm 0.01^{b, c}$ & $0.52 \pm 0.01^{b}$ & $3.80 \pm 0.26^{\mathrm{h}}$ \\
\hline \multirow{3}{*}{$10 \% \mathrm{CF}$} & 1 & $1.08 \pm 0.05^{b}$ & $1.00 \pm 0.00^{\mathrm{d}}$ & $0.88 \pm 0.03^{g}$ & $1.11 \pm 0.09^{b}$ \\
\hline & 2 & $3.39 \pm 0.22 \mathrm{~d}, \mathrm{e}$ & $0.97 \pm 0.01^{\mathrm{c}}$ & $0.62 \pm 0.04 \mathrm{~d}, \mathrm{e}$ & $2.09 \pm 0.21^{\mathrm{e}, \mathrm{f}}$ \\
\hline & 3 & $5.45 \pm 1.04^{\mathrm{f}}$ & $0.96 \pm 0.01^{b}$ & $0.50 \pm 0.02^{\mathrm{a}, \mathrm{b}}$ & $2.59 \pm 0.39^{\mathrm{f}, \mathrm{g}}$ \\
\hline \multirow{3}{*}{$15 \% \mathrm{CF}$} & 1 & $1.04 \pm 0.03^{b}$ & $1.00 \pm 0.00^{\mathrm{d}}$ & $0.85 \pm 0.03^{f}$ & $0.94 \pm 0.05^{\mathrm{a}}$ \\
\hline & 2 & $3.00 \pm 0.42^{c, d}$ & $0.96 \pm 0.01^{b}$ & $0.58 \pm 0.03^{c, d}$ & $1.62 \pm 0.23^{c, d}$ \\
\hline & 3 & $4.06 \pm 0.22 \mathrm{e}^{\mathrm{e}}$ & $0.94 \pm 0.02^{\mathrm{a}}$ & $0.47 \pm 0.03^{\mathrm{a}}$ & $2.01 \pm 0.24^{\mathrm{e}}$ \\
\hline \multirow{3}{*}{$20 \% \mathrm{CF}$} & 1 & $0.88 \pm 0.06^{\mathrm{a}}$ & $1.00 \pm 0.00^{\mathrm{d}}$ & $0.82 \pm 0.01^{\mathrm{f}}$ & $0.91 \pm 0.05^{a}$ \\
\hline & 2 & $2.64 \pm 0.31^{\mathrm{c}}$ & $0.94 \pm 0.02^{\mathrm{a}}$ & $0.56 \pm 0.03^{c}$ & $1.53 \pm 0.20^{c, d}$ \\
\hline & 3 & $3.94 \pm 0.83^{\mathrm{e}}$ & $0.93 \pm 0.02^{a}$ & $0.46 \pm 0.03^{a}$ & $1.91 \pm 0.49^{\mathrm{d}, \mathrm{e}}$ \\
\hline \multicolumn{6}{|c|}{ Two-way ANOVA-p } \\
\hline \multicolumn{2}{|c|}{ Factor A (level of additive) } & $<0.001$ & $<0.001$ & $<0.001$ & $<0.001$ \\
\hline \multicolumn{2}{|c|}{ Factor B (time) } & $<0.001$ & $<0.001$ & $<0.001$ & $<0.001$ \\
\hline \multicolumn{2}{|c|}{ Factor $\mathrm{A} \times$ Factor $\mathrm{B}$} & 0.014 & 0.005 & 0.798 & 0.909 \\
\hline
\end{tabular}

Mean value of four replications \pm standard deviation. Mean values signed the same letters in particular rows are not significantly different at 0.05 level of confidence.

On the day of baking, the crumb of control bread and loaves with $10-15 \%$ fiber content had the highest hardness. Only the replacement of starch with $20 \%$ fiber and corresponding increase in water addition caused a significant decrease in crumb hardness. During storage, the hardness of the loaves increased. The highest increase in hardness to over $7 \mathrm{~N}$ was observed in the case of the crumb of control bread, which clearly showed gradual staling. On the other hand, the crumb of loaves with the share of citrus fiber aged much slower, reaching on the third day of storage a hardness ranging from $3.94 \mathrm{~N}$ in the case of bread with the highest $20 \%$ share of fiber to $5.45 \mathrm{~N}$ in the case of bread with the lowest $10 \%$ share of fiber. The extent of crumb hardening retardation was clearly dependent on the amount of starch replaced by the fiber. It is also confirmed here by the results of the two-factor analysis of variance, where both the time and the share of fiber significantly affected the crumb hardness of bread (Table 3). Moreover, a negative linear correlation $(r=-0.97)$ between crumb hardness and porosity was observed. Additionally, Korus and Achremowicz [13] observed a significant decrease in gluten-free bread hardness after applying fiber preparations of various origins. A significant reduction in crumb hardness resulting from the presence of highly water-absorbent citrus fiber and, consequently, an elevated proportion of water in the recipe indicates that this ingredient, in addition to a significantly increasing the nutritional value of gluten-free bread, may be an effective factor-limiting staling process. The share of citrus fiber in the recipe and storage time also influenced the elasticity of the crumb of the analyzed bread. On the first day, all samples were characterized by the same elasticity. During storage, the elasticity of the crumb decreased when more fiber was introduced into the recipe. Due to the fact that fiber has a high ability to bind water, which also forces its greater share in the recipe, the crumb of the resulting bread becomes more moist, soft and susceptible to plastic deformation. The values of cohesiveness of the bread samples are presented in Table 3. Both the storage time and the level of fiber contribution had a significant impact on the cohesiveness values. The control bakery products were characterized by the highest cohesiveness both on the day of baking and during storage. Replacement of starch with citrus fiber resulted in a decrease in cohesiveness when more fiber was introduced into the recipe. In earlier studies, Ozturk and Mert used citrus fiber in combination with microfluidized corn gluten meal (CGM) in order to improve the quality of gluten-free bread. They observed an increase in bread volume, decrease in crumb hardness and parallel increase in its cohesiveness and 
springiness [28]. The apparent discrepancy seems to be related mainly to different control formulations (CGM + corn starch) as well as the level of the applied addition (below 10\%).

Since chewiness is closely correlated with hardness, the results of which are decisive for the values of this parameter, the effect of replacing starch with fiber was similar here. The crumb of control bread was characterized by the greatest chewiness both on the day of baking and during storage. On the other hand, the lowest values of chewiness were found for the crumb of bread with the highest proportion of citrus fiber. In a study concerning gluten-free bread based on rice flour and potato starch, O'Shea and co-workers [26] observed that the acceptability of "texture while chewing" was decreased after the addition of orange pomace, which was the only significant change in sensory assessment caused by this modification.

Korus and Achremowicz [13] observed a beneficial effect of apple and tomato fiber on slowing down crumb hardening during a four-day storage of gluten-free bread. Aprodu and Banu [14] found that the addition of various fiber preparations may affect dough cohesiveness and the pasting characteristics of starch present in it. A positive influence on crumb firmness was however observed only in the case of fiber isolated from Psyllium and pea. Ronda and co-workers [15], applying barley and oat beta-glucans as a source of fiber, reported a significant increase in the elasticity and viscosity of dough and a decrease in bread volume dependent on the molecular weight of applied preparations. Martínez et al. [16] in a study on the influence of various fiber fractions on dough properties concluded that soluble fiber reduces dough consistency, while the insoluble fraction causes its strengthening. They also observed that the presence of a soluble fraction of fiber improves the physicochemical characteristics of bread, which exhibits a larger volume and pore density and diminished hardness. Phimolsiripol et al. [17], when studying the effect of rice bran on the characteristics of gluten-free bread, found significant effects on improving crumb color and consumer acceptability, increasing the volume of the loaves and improving porosity and reducing firmness.

\section{Conclusions}

This study demonstrates the possibility of using citrus fiber as a component of gluten-free formulations based on the mixture of corn and potato starches, in order to improve the nutritional value of bread, modify its structure and slow down staling. The results indicate that the presence of citrus fiber modifies the rheological properties of the dough, increasing the values of storage and loss moduli and zero shear viscosity, and decreasing the compliance and tangent of the phase shift angle. A partial replacement of starch with citrus fiber resulted in a significant drop in apparent viscosity under flow in comparison to control dough. The presence of a highly water-absorbent substance caused structure strengthening in the range of small deformations, while at large deformations allowed easier flow. Thus, the rheological properties of the dough were improved, allowing it to be more susceptible to technological processing, including mixing, transport, and molding. The presence of citrus fiber caused a reduction in bread volume, accompanied by changes in crumb structure, such as a smaller number of pores per area, but greater porosity and increased pore size. The application of citrus fiber resulted in a decrease in hardness, springiness and chewiness of the crumb in comparison to control, and the change was proportional to the applied level of addition. A significant decrease in hardness and chewiness of crumb, caused by the presence of fiber with a high water binding capacity and the elevated water level in the bread formulation, indicates that such an addition could be effective not only for nutritional reasons but also for staling retardation. On the other hand, a decrease in the concentration of structure-forming gums caused by additional water has some negative effects, such as a decrease in bread volume, and an increase in size of pores.

Author Contributions: Conceptualization, J.K. and L.J.; methodology, J.K., L.J., M.W., R.Z.; formal analysis, L.J.; investigation, J.K., L.J., M.W., R.Z.; data curation, J.K., L.J., M.W., R.Z.; writing—original draft preparation, L.J.; writing-review and editing, J.K., L.J., M.W., R.Z.; supervision, J.K. All authors have read and agreed to the published version of the manuscript.

Funding: This research received no external funding. 
Conflicts of Interest: The authors declare no conflict of interest.

\section{References}

1. Kołodziejczyk, P.; Michniewicz, J. Cereal grains and cereal products as sources of dietary fibre. Food Sci. Technol. Qual. 2018, 116, 5-22. [CrossRef]

2. Sajdakowska, M.; Jeżewska-Zychowicz, M. Consumer attitudes towards bread and perception of bread with added fibre. Food Sci. Technol. Qual. 2017, 113, 113-125. [CrossRef]

3. Godula, K.; Czerniejewska-Surma, B.; Dmytrów, I.; Plust, D.; Surma, O. Possible applications of dietary fibre in functional food production. Food Sci. Technol. Qual. 2019, 119, 5-17. [CrossRef]

4. Witczak, T.; Juszczak, L.; Ziobro, R.; Korus, J. Rheology of gluten-free dough and physical characteristics of bread with potato protein. J. Food Process Eng. 2017, 40, e12491. [CrossRef]

5. Witczak, M.; Korus, J.; Ziobro, R.; Juszczak, L. Waxy starch as dough component and anti-staling agent in gluten-free bread. LWT Food Sci. Technol. 2019, 99, 476-482. [CrossRef]

6. Matos Segura, M.E.; Rosell, C.M. Chemical composition and starch digestibility of different gluten-free breads. Plant Food. Hum. Nutr. 2011, 66, 224. [CrossRef]

7. Hager, A.S.; Axel, C.; Arend, E.K. Status of carbohydrates and dietary fiber in gluten-free diets. CFW 2011, 56, 109-114. [CrossRef]

8. Melini, F.; Melini, V.; Luziatelli, F.; Ruzzi, M. Current and forward-looking approaches to technological and nutritional improvements of gluten-free bread with legume flours: A critical review. Compr. Rev. Food Sci. Food Saf. 2017, 16, 1101-1122. [CrossRef]

9. Naqash, F.; Gani, A.; Gani, A.; Masoodi, F.A. Gluten-free baking: Combating the challenges-A review. Trends Food Sci. Technol. 2017, 66, 98-107. [CrossRef]

10. Khoury, D.E.; Balfour-Ducharme, S.; Joye, I.J. A review on the gluten-free diet: Technological and nutritional challenges. Nutrients 2018, 10, 1410. [CrossRef]

11. Korus, J.; Witczak, M.; Ziobro, R.; Juszczak, L. The influence of acorn flour on rheological properties of gluten-free dough and physical characteristics of the bread. Eur. Food Res. Technol. 2015, 240, 1135-1143. [CrossRef]

12. Korus, J.; Witczak, M.; Ziobro, R.; Juszczak, L. Hemp (Cannabis sativa subsp. sativa) flour and protein preparation as natural nutrients and structure forming agents in starch based gluten-free bread. LWT Food Sci. Technol. 2017, 84, 143-150. [CrossRef]

13. Korus, J.; Achremowicz, B. Fiber preparations of different origin used as additives in baking gluten-free breads. Food. Sci. Technol. Qual. 2004, 38, 65-73.

14. Aprodu, I.; Banu, I. Influence of dietary fiber, water, and glucose oxidase on rheological and baking properties of maize based gluten-free bread. Food. Sci. Biotechnol. 2015, 24, 1301-1307. [CrossRef]

15. Ronda, F.; Perez-Quirce, S.; Lazaridou, A.; Biliaderis, C.G. Effect of barley and oat $\beta$-glucan concentrates on gluten-free rice-based doughs and bread characteristics. Food Hydrocolloids 2015, 48, 197-207. [CrossRef]

16. Martínez, M.M.; Díaz, Á.; Gómez, M. Effect of different microstructural features of soluble and insoluble fibres on gluten-free dough rheology and bread-making. J. Food Eng. 2014, 142, 49-56. [CrossRef]

17. Phimolsiripol, Y.; Mukprasirt, A.; Schoenlechner, R. Quality improvement of rice-based gluten-free bread using different dietary fibre fractions of rice bran. J. Cereal Sci. 2012, 56, 389-395. [CrossRef]

18. Garcia-Amezquita, L.E.; Tejada-Ortigoza, V.; Serna-Saldivar, S.O.; Welti-Chanes, J. Dietary fiber concentrates from fruit and vegetable by-products: Processing, modification, and application as functional ingredients. Food Bioprocess Technol. 2018, 11, 1439-1463. [CrossRef]

19. Fernández-López, J.; Fernández-Ginés, J.M.; Aleson-Carbonell, L.; Sendra, E.; Sayas-Barberá, E.; Pérez-Alvarez, J.A. Application of functional citrus by-products to meat products. Trends in Food Sci. Technol. 2004, 15, 176-185. [CrossRef]

20. Larrea, M.A.; Chang, Y.K.; Martinez-Bustos, F. Some functional properties of extruded orange pulp and its effect on the quality of cookies. LWT Food Sci. Technol. 2005, 38, 213-220. [CrossRef]

21. Kohajdová, Z.; Karovicová, J.; Jurasová, M.; Kukurová, K. Application of citrus dietary fibre preparations in biscuit production. J. Food Nutr. Res. 2011, 50, 182-190. 
22. Romero-Lopez, M.R.; Osorio-Diaz, P.; Bello-Perez, L.A.; Tovar, J.; Bernardino-Nicanor, A. Fiber concentrate from orange (Citrus sinensis, L.) bagase: Characterization and application as bakery product ingredient. Int. J. Mol. Sci. 2011, 12, 2174-2186. [CrossRef] [PubMed]

23. Talens, C.; Álvarez-Sabatel, S.; Rios, Y.; Rodríguez, R. Effect of a new microwave-dried orange fibre ingredient vs. a commercial citrus fibre on texture and sensory properties of gluten-free muffins. Innov. Food Sci. Emerg. Technol. 2017, 44, 83-88. [CrossRef]

24. Miller, R.A. Increased Yield of Bread Containing Citrus Peel Fiber. Cereal Chem. 2011, 88, 174-178. [CrossRef]

25. Ocen, D.; Xu, X. Effect of citrus orange (Citrus sinensis) by-product dietary fiber preparations on the quality characteristics of frozen dough bread. Am. J. Food Technol. 2013, 8, 43-53. [CrossRef]

26. O'Shea, N.; Doran, L.; Auty, M.; Arendt, E.; Gallagher, E. The rheology, microstructure and sensory characteristics of a gluten-free bread formulation enhanced with orange pomace. Food Funct. 2013, 4, 1856. [CrossRef]

27. O'Shea, N.; Rößle, C.; Arendt, E.; Gallagher, E. Modelling the effects of orange pomace using response surface design for gluten-free bread baking. Food Chem. 2015, 166, 223-230. [CrossRef]

28. Ozturk, O.K.; Mert, B. The use of microfluidization for the production of xanthan and citrus fiber based gluten-free corn breads. LWT Food Sci. Technol. 2018, 96, 34-41. [CrossRef]

29. Föste, M.; Verheyen, C.; Jekle, M.; Becker, T. Fibres of milling and fruit processing by-products in gluten-free bread making: A review of hydration properties, dough formation and quality-improving strategies. Food Chem. 2020, 306, 125451. [CrossRef]

30. Arslan, M.; Rakha, A.; Xiaobo, Z.; Mahmood, M.A. Complimenting gluten free bakery products with dietary fiber: Opportunities and constraints. Trends Food Sci. Technol. 2019, 83, 194-202. [CrossRef]

31. Korus, J.; Witczak, M.; Ziobro, R.; Juszczak, L. The impact of resistant starch on characteristics of gluten-free dough and bread. Food Hydrocolloids 2009, 23, 988-995. [CrossRef]

(C) 2020 by the authors. Licensee MDPI, Basel, Switzerland. This article is an open access article distributed under the terms and conditions of the Creative Commons Attribution (CC BY) license (http://creativecommons.org/licenses/by/4.0/). 